\title{
Improvement of Pavement Subgrade Soil using Millet Husk Ash for Rural Roads
}

\author{
Anish Kumar, Roop Kishor, Chaitanya Nidhi
}

\begin{abstract}
This paper focuses on the improvement of subgrade soil by using Millet Husk Ash (MHA). MHA is a commonly available material found in a significant quantity as India is the largest producer of millet in the entire world. The MHA was mixed in soil by partially replacing the soil by weight in $0 \%, 2.5 \%, 5 \%, 7.5 \%, 10 \%, 12.5 \%$ and $15 \%$. The soil in its natural state was in the form of intermediate plastic clay whose dry density got reduced and the optimum moisture content got increased after stabilization. The CBR and UCS values increased initially but showed a decrease after a certain point. The sudden transition from increasing values to decreasing values marks a peak point showing the optimum content of MHA. The optimum content of the ash was found to be $10 \%$. A significant increase in the values of UCS and CBR was also observed.
\end{abstract}

Keywords: MHA, Pavement, CBR, UCS

\section{INTODUCTION}

India is the largest producer of millet in the entire world with a share of $40 \%$ of the entire production. MHA is obtained by burning millet husk after removing the seeds from it. Millets can sustain adverse climatic conditions and can easily give high yield. They are rich in amino acids and are excellent source of protein. Thus, we can say that the use of MHA has dual benefits, the millets itself can be consumed and the husk can be used to prepare MHA. Since the CBR values of Alluvial soils are very low, an effective low cost technique should be evolved to stabilize the soil which is suitable for rural roads.In previous research it was found that theOMC increasesand the dry density was decreased asthe ash content in the soil is increased( Aditya kumar Anupam et al. 2013). The thickness of the pavement decreases asthe ash content was increased from 0 to $12.5 \%$, the optimum value of the ash content was 7.5\% (A. Kumar et al. 2017).

Revised Manuscript Received on April 13, 2020.

* Correspondence Author

Anish Kumar*, Assistant Professor, Department of Civil Engineering, Rajkiya Engineering College, Azamgarh, Uttar Pradesh, IndiaEmail: anishce0009@gmail.com

Roop Kishor, Research Scholar, Department of Civil Engineering, Motilal Nehru National Institute of Technology Allahabad, Uttar Pradesh, India Email: roopkishor764@gmail.com

Chaitanya Nidhi, Assistant Professor, Department of Civil Engineering, Rajkiya Engineering College, Azamgarh, Uttar Pradesh, India Email: chaitanya.nidhi@gmail.com

(C) The Authors. Published by Blue Eyes Intelligence Engineering and Sciences Publication (BEIESP). This is an open access article under the CC BY-NC-ND license (http://creativecommons.org/licenses/by-nc-nd/4.0/)
A significant improvement in California Bearing Ratio was seen when clayey soil was mixed with rice husk ash (10\%) and lime (9\%) (B.S. Kumar et al. 2014). In a separate research it was found that with increase the proportion of rice husk ash and cement, optimum moisture content and CBR increases whereas maximum dry density decreases (Roy Aparna et al. 2014). The effect of MHA and cutback Bitumen on the durability properties of laterite soil (Suleiman et al. 2017). The study showed that the mix of laterite soil and MHA $(30 \%)$ when admixed with $8 \%$ cutback bitumen gives the optimum compressive strength. They also mentioned that MHA and Bitumen acted as pozzolanic material in performance tests. A study shows that the partial replacement of cement with $20 \%$ millet husk ash is recommended in sandcrete block production (Solomon et al.2017).

\section{A. Use of locally available materials}

The locally available materials have tremendous potential to serve as excellent stabilizers. India is a large country with a majority of people residing in rural areas and these rural areas should have good quality roads in order to facilitate the movement of people, farm yield, cattle etc. These areas should also be connected to the nearby urban cities through good roads. The soft nature of alluvial soils and poor drainage conditions in rural areas proves to be a lethal combination for the health of the subgrade. This demands regular maintenance which comes at high cost. The cost and frequency of maintenance can be reduced by using locally available stabilizers.

\section{B. Scope and Objectives}

The study was focused to enhance the strength of the subgrade soil by using locally available material. The following were the objectives of the study:

a.To explore the potential of MHA as an effective soil stabilizer.

b. To examine the chemical and physical properties of the stabilizer.

c.To examine the chemical and physical properties of virgin soil and soil at $2.5 \%, 5 \%, 7.5 \%, 10 \%, 12.5 \%$ and $15 \%$ replacement.

\section{LABORATORY INVESTIGATIONS AND RESULTS:}

A. Virgin Soil: The alluvial disturbed soil sample was collected from, Azamgarh, Uttar Pradesh. The soil was dugged out from a depth of $1 \mathrm{~m}-2 \mathrm{~m}$.

Published By:

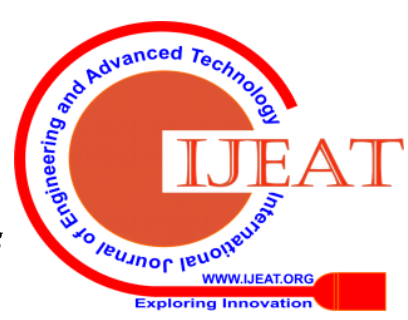


B. The grain size distribution curve shown in the Figure 1. The geotechnical properties of the natural soil sample given in the Table 1.
C. Grain Size Distribution: Grain size of the soil was determined on the basis of the sieve and hydrometer analysis, the combined graph shown in the Figure 1.

\begin{tabular}{|c|c|c|c|c|c|c|c|}
\hline SOIL & LL & PL & PI & OMC & MDD(g/cc) & CBR (\%) & UCS(g/cc) \\
\hline Virgin Soil & 49 & 29.24 & 19.76 & 18.24 & 1.66 & 2.1 & 1.5 \\
\hline
\end{tabular}

Table 1. Geotechnical Properties of Virgin Soil

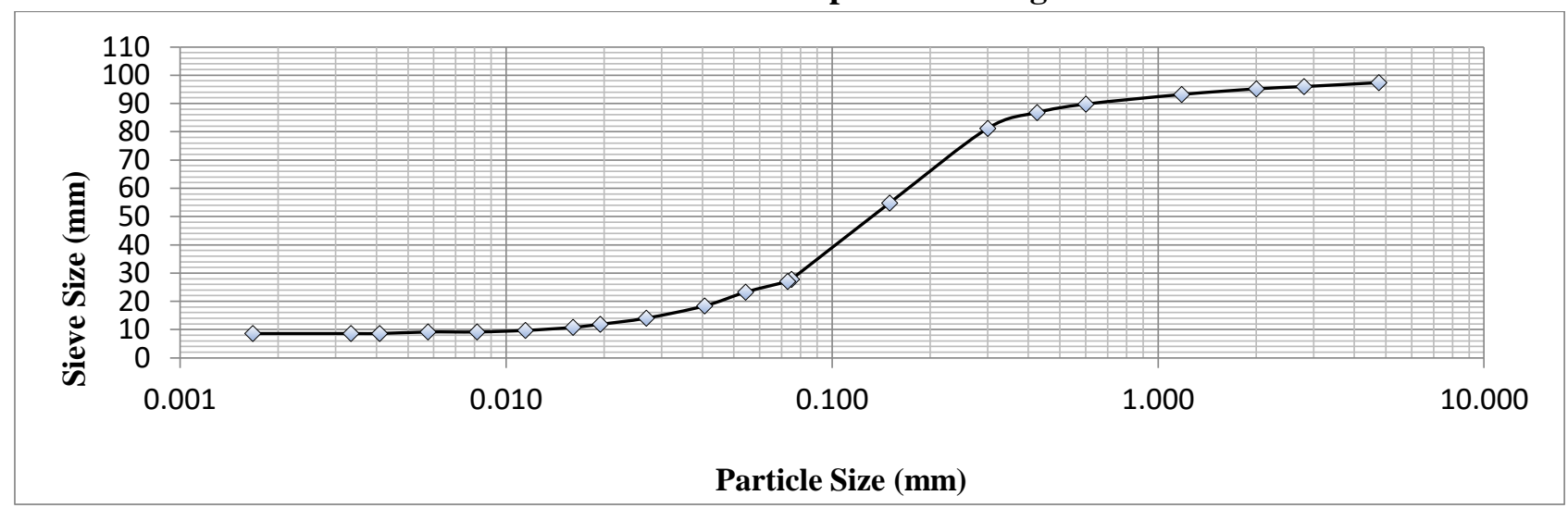

Table 2. Chemical Properties of MHA

\begin{tabular}{|c|c|c|c|c|}
\hline Constituent & \% Content & & & \\
\hline $\mathrm{SiO} 2$ & 63.7 & & & \\
\hline $\mathrm{Al} 2 \mathrm{O} 3$ & 3.80 & & & \\
\hline $\mathrm{Fe} 2 \mathrm{O} 3$ & 2.60 & & Property & Result \\
\hline $\mathrm{CaO}$ & 0.02 & & Colour & Light grey \\
\hline $\mathrm{MgO}$ & 0.03 & & Specific Gravity & 1.88 \\
\hline $\mathrm{Na} 2 \mathrm{O}$ & 1.14 & & Liquid Limit (\%) & 46 \\
\hline $\mathrm{K} 2 \mathrm{O}$ & 20.1 & & Plastic Limit (\%) & Non plastic \\
\hline $\mathrm{P} 2 \mathrm{O} 3$ & 4.10 & & OMC (\%) & 43.23 \\
\hline $\mathrm{MnO}$ & 0.05 & & MDD (gm/cc) & 1.17 \\
\hline $\mathrm{SO} 3$ & 2.06 & & Table 3.Physical Properties of MHA \\
\hline $\mathrm{TiO} 3$ & 0.16 & & & \\
\hline $\mathrm{Cl}$ & 2.15 & & & \\
\hline $\mathrm{Br}$ & 0.07 & & \multicolumn{2}{c}{} \\
\hline
\end{tabular}

C.Millet Husk ash: The millet husk ash was collected from the Rani Ki Sarai, Azamgarh, Uttar Pradesh. This husk ash was obtained from the burning of millet husk at the $500-600^{\circ} \mathrm{C}$ temperature. The chemical composition of the millet husk ash was determined by the XRF analysis, it is given in the Table 2. The physical properties of MHA are given in Table.3.

\section{Atterberg's Limit at various proportions of soil and MHA:}

a. Liquid limit: Liquid limit of the soil sample and the soil mixed with MHA was determined as per IS 2720 Part-5. It is observed that the liquid limit of the soil mixed with the MHA is decreased as the admixture in the soil is increased. Observations of the liquid limit given in the Table 4.

b. Plastic limit: Plastic limit of the soil sample and the soil mixed with MHA was determined as per the IS 2720 Part-5. It is observed that the plastic limit of the soil mixed with the MHA decreased as per the increases the admixture in the soil. Observation of the plastic limit given in the Table 4.

c. Plasticity Index: Plasticity index of the soil sample decreases with an increase of the admixture in the soil. It is shown in the Figure 2.

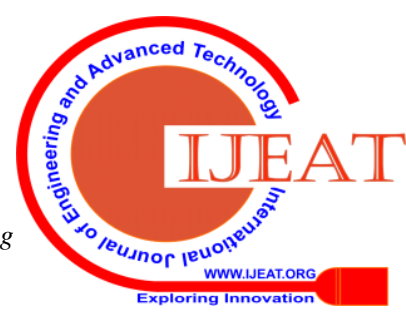




\begin{tabular}{|c|c|c|l|}
\hline $\begin{array}{c}\text { SOIL(\%): } \\
\text { MHA(\%) }\end{array}$ & LL (\%) & PL (\%) & PI (\%) \\
\hline $100: 0$ & 49 & 29.24 & 9.76 \\
\hline $97.5: 2.5$ & 45 & 29.35 & 5.65 \\
\hline $95: 5$ & 42 & 28.95 & 3.05 \\
\hline $92.5: 7.5$ & 41 & 27.67 & 3.33 \\
\hline $90: 10$ & 38 & 27.23 & 0.77 \\
\hline $87.5: 12.5$ & 37 & 25.83 & 1.17 \\
\hline $85: 15$ & 36 & 24.32 & 1.68 \\
\hline
\end{tabular}

Table 4. Atterberg's Limit at various Proportions of soil and MHA

\begin{tabular}{|c|l|l|}
\hline SOIL (\%): MHA(\%) & OMC (\%) & MDD(g/cc) \\
\hline $100: 0$ & 18.24 & 1.66 \\
\hline $97.5: 2.5$ & 19.21 & 1.62 \\
\hline $95: 5$ & 20.25 & 1.61 \\
\hline $92.5: 7.5$ & 21.04 & 1.59 \\
\hline $90: 10$ & 22.13 & 1.58 \\
\hline $87.5: 12.5$ & 23.10 & 1.56 \\
\hline $85: 15$ & 24.06 & 1.55 \\
\hline
\end{tabular}

Table:5 Optimum Moisture Content and Maximum Dry Density at various proportion of soil and MHA

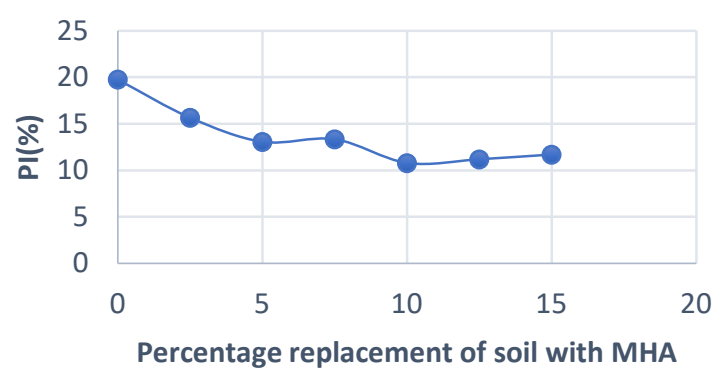

Figure 2. Plasticity index at the various proportion of soil and MHA.

d. Optimum moisture content and maximum dry density: Optimum moisture content and maximum dry density of soil and mixed with MHA were determined as per IS 2720 (Part-7). The Maximum dry density of the soil was decreased when the MHA increases and optimum moisture content of the soil was increased as MHA was increased in the soil.

e. Soaked California Bearing Ratio at various proportion of soil and MHA: The California bearing ratio of the subgrade soil was determined as per the IS 2720 Part-16. The CBR value of the subgrade soil showed an increase up to $10 \% \mathrm{MHA}$ and the CBR value starts to decrease with further increase in MHA.

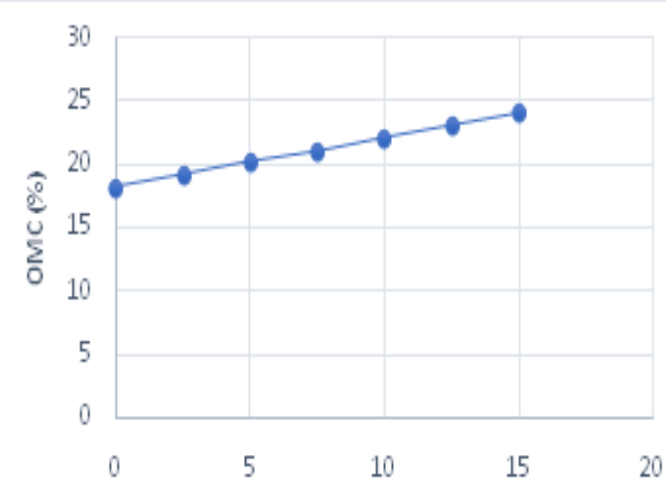

Percentage replacemnt of soil with MHA

Fig 3. OMC at various proportion of soil and MHA

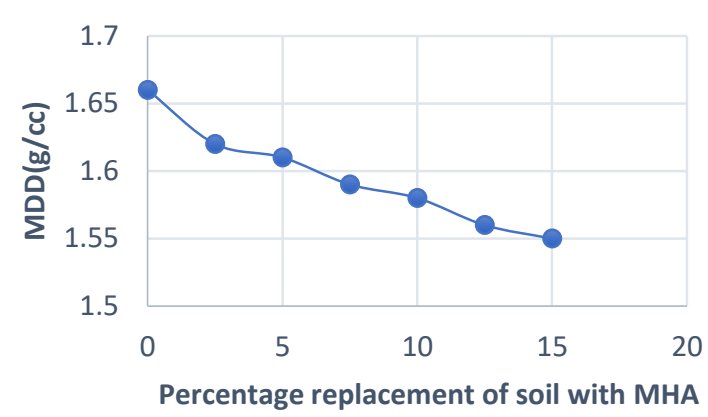

Figure 4. Maximum dry density at various

\begin{tabular}{|c|c|} 
proportion of soil and MHA \\
\hline SOIL(\%): MHA(\%) & $\begin{array}{c}\text { CBR } \\
(\%)\end{array}$ \\
\hline $100: 0$ & 2.1 \\
\hline $97.5: 2.5$ & 3.2 \\
\hline $95: 5$ & 4.73 \\
\hline $92.5: 7.5$ & 5.24 \\
\hline $90: 10$ & 6.28 \\
\hline $87.5: 12.5$ & 5.15 \\
\hline $85: 15$ & 5.12 \\
\hline
\end{tabular}

Table 6. Soaked CBR at various proportion of soil and MHA

f. Unconfined compressive strengthat various proportions of soil and MHA:

UCS value of the subgrade soil was determined as per the IS 2720 Part-10. The unconfined compressive strength of the subgrade increases up to $10 \% \mathrm{MHA}$ and then decreases with further increase of the MHA in the soil.

g.Effect of MHA stabilised soil on total thickness of pavement:Thickness of the pavement were determined as per the IRC-SP: $72-2015$ at the virgin soil and modified soil shown in figure: and the various traffic category T1, T2, Т3...T9.

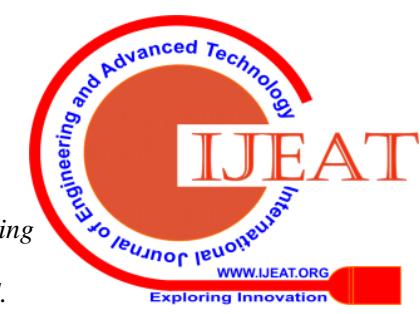


Improvement of pavement subgrade soil using millet husk ash for rural roads

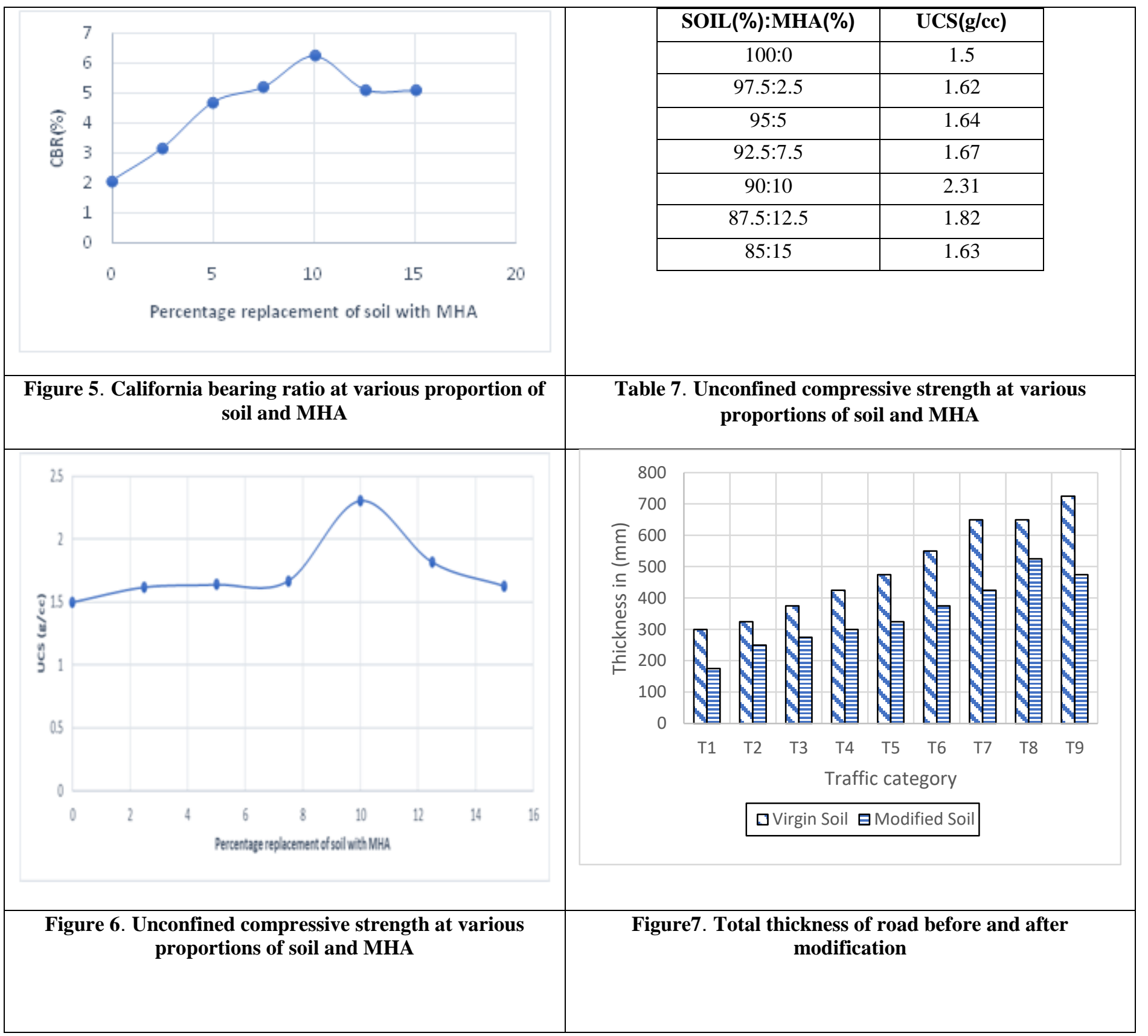

\section{CONCLUSIONS}

After conducting various tests and studying their results following conclusions have been made:

a. The natural soil was classified as Intermediate Plastic Clay as per Indian Standard Soil Classification System.

b. The Millet Husk Ash showed appreciable cementitious property due to the presence of oxides of alumina and silica in higher amounts.

c. The plasticity index of the soil mixed with MHA decreases with the corresponding increase in the quantity of MHA. The MHA was varied from $2.5 \%$ to $15 \%$.

d. The soaked CBR of the soil initially increases up to a specific point then a decrease in the soaked CBR values is seen. The optimum values of MHA and soil were $10 \%$ and $90 \%$ respectively.

e. The UCS values also followed a similar trend like that of CBR. The optimum values of MHA and soil were $10 \%$ and $90 \%$ respectively. f. The maximum values of UCS and CBR at $10 \%$ MHA indicates the optimum value of MHA that can be used for stabilizing the soil of similar nature under similar climatic conditions.

g. The thickness of the subgrade is also appreciably reduced by using MHA stabilised soil and thereby reducing the construction as well as maintenance cost.

\section{REFERENCES}

1. Adrian. OshionameEberemu and Abubakar Sadiq Muhammed (2017) "The remediation potential of ordinary portland cement (opc) admixed with millet husk ash (MHA) on a scrap metal dump site contaminated soil" Proceedings of the 2nd Symposium on Coupled Phenomena in Environmental Geotechnics (CPEG2), Leeds, UK.

2. Anupam Aditya Kumar et al., (2013). "Use of Various Agricultural and Industrial Waste Materials in Road Construction.” Procedia - Social and Behavioral Sciences 104, 264 - 273.

\section{Published By:}

Blue Eyes Intelligence Engineering

\& Sciences Publication

(C) Copyright: All rights reserved.

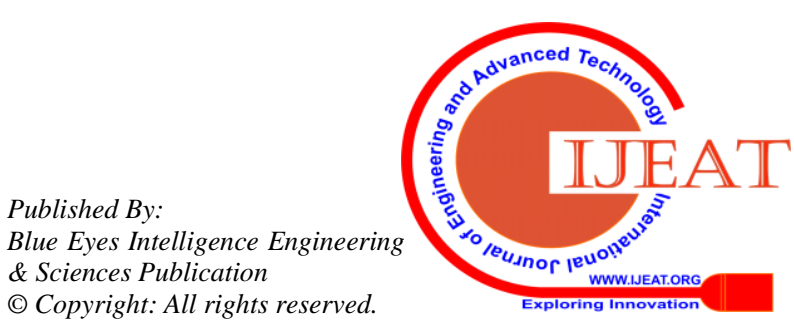


3. Anupam Aditya Kumar, et al., (2017). "Study on Performance and Efficacy of Industrial Waste Materials in Road Construction: fly ash and bagasse ash." Airfield and Highway Pavements. 45-56.

4. Jimoh. R. Ajayi et al. (2013). "Exploratory assessment of strength characteristics of millet husk ash (MHA) blended cement laterized concrete" Advances in Applied Science Research, 4(1):452-457.

5. Kumar, B.S., and Preethi, T.V., (2014). "Behavoiur of clayey soil stabilized with rice husk ashand lime”, Int.J. Eng. Trend Technol.11 (1), pp. 44-48.

6. Roy Aparna, (2014). "Soil stabilization using rice husk ash and cement," in Int. J. Civil Eng. Res., 5(1), pp.49-54.

7. Solomon et al. (2017). "Millet husk ash as partial replacement of cement in sandcrete block", International Research Journal of Engineering and Technology, Vol.4, Issue.7.

8. Suleiman et al. (2017). "Durability Properties of Millet Husk Ash (MHA)

Stabilized Soil Block Admixed with Bitumen”. Journal of Research Information in Civil Engineering, Vol.14, No.2.

9. Yadav, A.K., Gaurav K., Kishor, R. and Suman, S.K. (2017) "Stabilization of alluvial soil for subgrade using rice husk ash, sugarcane bagasse ash and cow dung ash for rural roads". International journal of pavement research and technology, 10, pp.254-261.

\section{AUTHORS PROFILE}

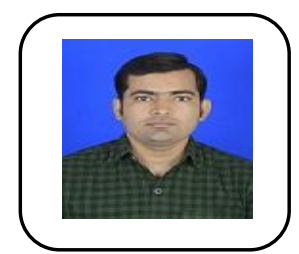

Anish Kumar, Assistant Professor, Department of Civil Engineering, Rajkiya Engineering College, Azamgarh, Uttar Pradesh, India. M.Tech (Transportation Engineering) from National Institute of Technology, Patna, Bihar, India

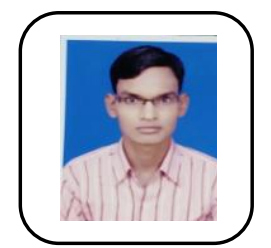

RoopKishor, Research Scholar, Department of Civil Engineering, Motilal Nehru National Institute of Technology Allahabad, Uttar Pradesh, India.M.Tech (Transportation Engineering) from National Institute of Technology, Patna, Bihar, India

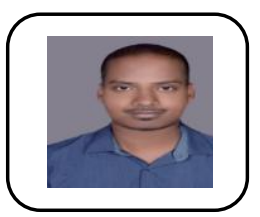

Chaitanya Nidhi, Assistant Professor, Department of Civil Engineering, Rajkiya Engineering College, Azamgarh, Uttar Pradesh, India. M.Tech (Civil Engineering) from Motilal Nehru National Institute of Technology, Allahabad, U.P

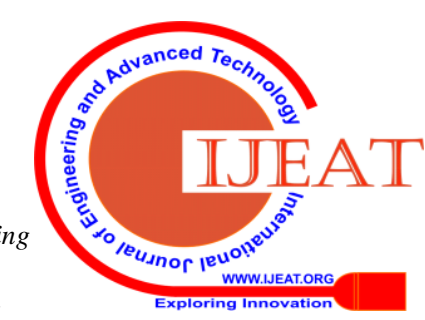

